\title{
Optimisation of repair and maintenance costs for electrical equipment in agricultural enterprises
}

\author{
Valery Zhdanov, Elena Logacheva, Viktor Yarosh, and Alexander Ivashina \\ Stavropol State Agrarian University, 12 Zootechnicheskiy Ln, Stavropol, 355017, Russian Federation
}

\begin{abstract}
Application of mathematical methods of cost optimization for repair and maintenance of electrical equipment of agro-industrial enterprises is one of the important and promising directions for increasing the efficiency of electrical equipment operation management in agriculture. Mathematical programming systems use graphical and related attributive information in solving optimization problems. As graphical information in these systems we used maps, plans, diagrams, schedules of preventive measures from which the list of equipment for certain types of repair and maintenance, their labor intensity for individual objects, types of equipment and in total for the enterprise are established. Databases of electrical equipment are used as attributive information to describe electrical equipment of agro-industrial enterprises. Due to joint processing of graphical and attributive information in optimization systems, all stages of work with spatial data are more operative. Beginning from spatial data search, selection and analysis we can make a specific decision during the operation control of electrical equipment. This article considers maintenance and repair operation (MR) as a task of mathematical programming with cost optimization and deals with three approaches to the organization of this task. The expediency of using each method of solution is analyzed. The structural schemes, equations describing mathematical models, advantages and disadvantages of the presented models are given. We marked prospect of using linear programming programs for the decision of the given optimization problem by means of the inverse matrix method, i.e. the modified simplex method and computing algorithm with a standard sequence of operations.
\end{abstract}

\section{Introduction}

A modern agricultural enterprise can use both its own repair facilities to carry out maintenance and repair work on electrical equipment and can use specialist electrical repair organizations. It is not uncommon for enterprises to use the services of several contractors that may perform different or even the same types of work. From this situation the necessity of solving the problem of rational use of own electrical service and specialized repair companies arises.

As it has to be solved annually, let us set the operation of maintenance and repair as a mathematical programming problem.

First of all, when posing the problem, let us ask, whether there are alternatives for realization of the purpose of this operation - unconditional fulfillment of schedule of maintenance and repair of electric equipment. Many of them are obvious: the possibility of carrying out repairs only by own electrical service; the possibility of carrying out repairs only by contracting specialized organizations; the possibility of carrying out repairs both by own efforts and with the help of external (one or more) organizations [1, 2].

Achievement of the purpose of operation with such a large number of alternatives is limited by a number of circumstances: impossibility of performance of a difficult part of repair work by own electro technical personnel; possibility of performance by specialized enterprises only certain types of electric equipment; limited right to use services of this or that specialized electrical repair organization (repair quota); limited number of personnel of own electrical repair service, etc.

Since the implementation of the equipment MR schedule is financed from the management budget, we will take this item of expenditure as a criterion for the implementation of the maintenance and repair operation and will minimize it.

\section{Materials and methods}

Let us consider the information requirements for the task and the possibilities of obtaining it. Much of the information can be obtained from the schedule of maintenance of electrical equipment prepared by the electrical service of the agricultural enterprise on the eve of a new economic year. From this schedule it is possible to establish a list of equipment, which in the coming year must undergo a certain type of maintenance and repairs, labour intensity of maintenance and repairs by individual objects, by types of equipment and in total for the enterprise. The cost of a unit of maintenance work can be calculated or readily available based on the size and qualifications of the maintenance personnel, the

* Corresponding author: jdanow.valery@yandex.ru 
consumption of resources and the overhead costs of the workshops. External specialized organizations will be asked for information about the costs of their repairs by type of work and the overall labour costs. The information described above is deterministic because it is inherently free of uncertainty (the equipment is known, labour inputs are standardized and the plans of the outside organizations have been formed) [3, 4].

Let us make the following assumption. Assume that the unit price of repairs made by its own electrical service and external entities do not depend on the amount of repairs (prices are linear) and the quality of repairs is the same high.

Let us now formulate the problem verbally. Knowing total labour input of repair, its distribution on kinds of the equipment, set of the electrical repair organizations and their repair quotas for the considered enterprise, to synthesize optimal plan of MR schedule realization for the electrical equipment, taking into account possibilities on labour of executors of repair works and providing minimum of expenses for maintenance and repair.

As controlled variables, vector $X$ is accepted, the components of which are labor inputs of maintenance (repair) of $i$-th type of equipment in $j$-th repair enterprise (here, the enterprise means both own electrical service and external specialized organizations). Let us set the dimensionality of the vector $X$. Since for each type of equipment the maintenance (repair) can be performed by any enterprise or even by all enterprises in parts, the vector of variables will be a dimensional column. For example, if $i=10$ and $j=3$, the vector of controlled variables will contain at least 30 components. They are all non-negative in nature and continuous.

But the controlled variables considered are not the only possible ones. It is possible to take as controlled variables not the labour intensity of repairs, but the fact that the $i$-th type of equipment is assigned to maintenance (repair) by the $j$-th enterprise $-y_{i j}$. Let us assign to these variables values equal to 1 if the $i$-th type of equipment is maintained (repaired) by the $j$-th enterprise and 0 - otherwise. Therefore, the variables are non-negative. The number of variables in the control vector will still be the same, but now they are discrete and hence the structure of the model should guarantee that the optimal solution could be obtained in integers. Let us accept the following designations

- $x_{i j}$ - labour intensity of maintenance (repairs) of the $\mathrm{i}$-th type of equipment carried out by the $\mathrm{j}$-th repair enterprise;

- $c_{i j}$ - unit cost of maintenance (repairs) of i-th kind of equipment, carried out by $\mathrm{j}$-th repair enterprise;

- $a_{i}$ - total labour input of technical maintenance (repairs) of the i-th type of equipment;

- $b_{j}$ - total labour input of technical maintenance (repairs), which can be realized by $\mathrm{j}$-th repair enterprise;
- $\mathrm{C}$ - costs for realization of schedule of technical maintenance and repairs.

Based on the verbal formulation of the problem, let us write the model as follows:

$$
\left.\begin{array}{c}
C\left(x_{i j}\right) \rightarrow \text { min } ; \\
\sum_{j} x_{i j}=a_{i} ; \\
\sum_{i} x_{i j} \leq b_{j} ; \\
x_{i j} \geq 0 .
\end{array}\right\} .
$$

The meaning of all $\sum_{j} x_{i j}=a_{i}$ type constraints is that the MR schedule will necessarily be completed. The number of these constraints in the model is equal to the number of equipment types $[5,6]$.

The meaning of all $\sum_{j} x_{i j}=a_{i}$ type constraints is that the load of the enterprises involved in the maintenance (repair) of equipment will be made in accordance with their capabilities.

There will be no more such constraints than the number of enterprises. The signs of the inequality will be determined by the capacity of the enterprises.

If these capabilities are defined as follows. The enterprise has to perform the maintenance (repairs) of the specified volume, the constraint will change to an equal. If the enterprise is unable to perform less than a certain volume, the constraint will show the " $\geq$ " sign and if, finally, the enterprise is ready to perform no more than a fixed volume, the constraint is to be written with the " $\leq$ "sign.

To present the model (1) in a functional form, it is only necessary to disclose the content of the target function $C$, reflecting the costs of implementing the MR schedule at different allocations of repair work by enterprises. Then definitively:

$$
\left.\begin{array}{c}
C=\sum_{i} \sum_{j} c_{i j} x_{i j} \rightarrow \min ; \\
\sum_{j} x_{i j}=a_{i} ; \\
\sum_{i} x_{i j}{ }^{\leq} b_{j} ; \\
x_{i j} \geq 0 \mid i=1,2, \ldots ; j=1,2, \ldots .
\end{array}\right\}
$$

The vector $x=\left(x_{1}, x_{2}, \ldots x_{n}\right)^{t}$, whose components satisfy the constraints in (2), is called a control vector.

Let us write down a functional model of the same operation with $y_{i j}$, discrete controlled variables reflecting the fact of assigning the $i$-th type of equipment for maintenance (repair) by $j$-th enterprise; 
other designations in the model below remain the same:

$$
\left.\begin{array}{c}
C=\sum_{i} \sum_{j} a_{i} c_{i j} y_{i j} \rightarrow \min ; \\
\sum_{i} y_{i j}=1 ; \\
y_{i j} \geq 0 \mid i=1,2, \ldots j=1,2, \ldots
\end{array}\right\}
$$

The economic meaning of the target function and constraints of models (1)-(3) is completely identical. This completes the definition of maintenance and repair operation as a mathematical programming problem [7]. In order to optimise costs, we use the program for solving the linear programming problem using the inverse matrix method (modified simplex method) and use a computational algorithm with a standard sequence of operations.

\section{Results and discussion}

The conducted analysis of expenses for the annual schedule of technical maintenance and repairs of electrical equipment of Grachevsky elevator of the Stavropol Territory showed the effectiveness of the solution of this problem [3].

The annual labor input of technical maintenance and current repairs of the electrical equipment of the enterprise was 111296 man-hours and consists of the set of works on maintenance of control and measuring devices and automatics (MD\&AC), electric motors, starting protection equipment, power and lighting switchboards, lighting fixtures, electric wiring.

The company's own electrical service can provide not more than 8032 person-hours of work. The rest of the work is outsourced to a specialized repair company. The basic data on the amount of work are given in Table 1.

Table 1. Technical and economic information on the scope of repair work.

\begin{tabular}{|c|c|c|c|c|c|}
\hline $\begin{array}{c}\text { Equipment } \\
\text { type }\end{array}$ & $\begin{array}{c}\text { Labour } \\
\text { intensity, } \\
\text { person - } \\
\text { hours }\end{array}$ & Enterprise & $\begin{array}{c}\text { Specialised } \\
\text { organisation }\end{array}$ & $\begin{array}{c}\text { Own maintenance } \\
\text { and repair costs, } \\
\text { RUB/person/hour }\end{array}$ & $\begin{array}{c}\text { The cost of TOR in a } \\
\text { specialised } \\
\text { organisation, } \\
\text { rub/person/hour }\end{array}$ \\
\hline MD\&AC & 1839.6 & $x_{1}$ & $x_{2}$ & 40.5 & 40.0 \\
Electric & 2858.8 & $x_{3}$ & $x_{4}$ & 45.0 & 46.0 \\
motors & 1274.7 & $x_{5}$ & $x_{6}$ & 38.0 & 46.5 \\
SAV & 3189.4 & $x_{7}$ & $x_{8}$ & 44.5 & 36.5 \\
Power, & & $x_{9}$ & $x_{10}$ & 35.0 & 43.0 \\
lighting & 513.4 & $x_{11}$ & $x_{12}$ & 40.0 & \\
panels, lamps & 1610.8 & & & & \\
Wire & & & & & \\
Cable & & & &
\end{tabular}

It is required to determine the optimum strategy for the implementation of works on the MR of the enterprise.

By substituting numerical values into equation (2) we obtain the following expression to determine the target function:

$$
\begin{aligned}
& C=40.5 x_{1}+40 x_{2}+45 x_{3}+46 x_{4}+38 x_{5}+36.5 x_{6}+ \\
& +44 x_{7}+46 x_{8}+36 x_{9}+36,5 x_{10}+40 x_{11}+43 x_{12} .
\end{aligned}
$$

Limitations reflecting the mandatory completion of the entire scope of work:

$$
\begin{array}{ll}
x_{1}+x_{2}=1839.6 ; & x_{3}+x_{4}=2858.8 ; \\
x_{5}+x_{6}=1274.7 ; & x_{7}+x_{8}=3189.4 ; \\
x_{9}+x_{10}=513.4 ; & x_{11}+x_{12}=1610.8 .
\end{array}
$$

Since the condition of the problem notes the limited capacity of the company's own electrical repair facilities, this fact is mathematically reflected as follows:

$x_{1}+x_{3}+x_{5}+x_{7}+x_{9}+x_{11} \leq 8032$.
The result is a mathematical model in the functional form:

$$
\left.\begin{array}{l}
40.5 x_{1}+40 x_{2}+45 x_{3}+46 x_{4}+38 x_{5}+36.5 x_{6}+ \\
+44,5 x_{7}+46 x_{8}+36 x_{9}+36.5 x_{10}+ \\
+40 x_{11}+43 x_{12} \rightarrow \text { min; } \\
x_{1}+x_{2}=1839.6 \\
x_{3}+x_{4}=2858.8 \\
x_{5}+x_{6}=1274.7 \\
x_{7}+x_{8}=3189.4 ; \\
x_{9}+x_{10}=513.4 ; \\
x_{11}+x_{12}=1610.8 ; \\
x_{1}+x_{3}+x_{5}+x_{5}+x_{7}+x_{9}+x_{11} \leq 8032 ; \\
x_{i} \geq 0, i=1,2, \ldots, 6 .
\end{array}\right\}
$$


In order to check the compatibility of the constraints, let us represent them in the form (4). To do this, we need to get rid of one constraint, an inequality. Its representation in the form of an equation can be done by introducing one additional non-negative $x_{13}$ variable according to the following scheme:

$$
\begin{aligned}
& x_{1}+x_{3}+x_{5}+x_{7}+x_{9}+x_{11} \leq 8032 \\
& x_{1}+x_{3}+x_{5}+x_{7}+x_{9}+x_{11}-8032 \leq 0 \\
& -x_{1}-x_{3}-x_{5}-x_{7}-x_{9}-x_{11}+8032 \geq 0 ; \\
& x_{13}=-x_{1}-x_{3}-x_{5}-x_{7}-x_{9}-x_{11}+8032 \\
& x_{1}+x_{3}+x_{5}+x_{7}+x_{9}+x_{11}+x_{13}=8032 \\
& x_{i} \geq 0, i=1,2, \ldots, 13 .
\end{aligned}
$$

Considering the work done, the constraint system of the model, defined on the set of nonnegative numbers, has the form:

$x_{1}+x_{2}=1839.6$;

$x_{3}+x_{4}=2858.8$;

$x_{5}+x_{6}=1274.7$;

$x_{7}+x_{8}=3189.4$;

$x_{9}+x_{10}=513.4$;

$x_{11}+x_{12}=1610.8$;

$x_{1}+x_{3}+x_{5}+x_{7}+x_{9}+x_{11}+x_{13}=8032$;

$x_{i} \geq 0, i=1,2, \ldots, 13$.

The matrix of this system:

$\left|\begin{array}{lllllllllllll}1 & 1 & 0 & 0 & 0 & 0 & 0 & 0 & 0 & 0 & 0 & 0 & 1 \\ 0 & 0 & 1 & 1 & 0 & 0 & 0 & 0 & 0 & 0 & 0 & 0 & 0 \\ 0 & 0 & 0 & 0 & 1 & 1 & 0 & 0 & 0 & 0 & 0 & 0 & 0 \\ 0 & 0 & 0 & 0 & 0 & 0 & 1 & 1 & 0 & 0 & 0 & 0 & 0 \\ 0 & 0 & 0 & 0 & 0 & 0 & 0 & 0 & 1 & 1 & 0 & 0 & 0 \\ 0 & 0 & 0 & 0 & 0 & 0 & 0 & 0 & 0 & 0 & 1 & 1 & 0 \\ 1 & 0 & 1 & 0 & 1 & 0 & 1 & 0 & 1 & 0 & 1 & 0 & 1\end{array}\right|$

and its rank $r=7$. Extended matrix of the same system:

$\left|\begin{array}{cccccccccccccc}1 & 1 & 0 & 0 & 0 & 0 & 0 & 0 & 0 & 0 & 0 & 0 & 0 & 1839,6 \\ 0 & 0 & 1 & 1 & 0 & 0 & 0 & 0 & 0 & 0 & 0 & 0 & 0 & 2858,8 \\ 0 & 0 & 0 & 0 & 1 & 1 & 0 & 0 & 0 & 0 & 0 & 0 & 0 & 1274,7 \\ 0 & 0 & 0 & 0 & 0 & 0 & 1 & 1 & 0 & 0 & 0 & 0 & 0 & 3189,4 \\ 0 & 0 & 0 & 0 & 0 & 0 & 0 & 0 & 1 & 1 & 0 & 0 & 0 & 513,4 \\ 0 & 0 & 0 & 0 & 0 & 0 & 0 & 0 & 0 & 0 & 1 & 1 & 0 & 1610,8 \\ 1 & 0 & 1 & 0 & 1 & 0 & 1 & 0 & 1 & 0 & 1 & 0 & 1 & 8032\end{array}\right|$ has rank $\mathrm{r}=7$ too and therefore the constraint system is joint. In this sense, the problem is set correctly.

Here is the optimum control vector.

$X=|01839.62858 .8001274 .73189 .40373140 .41610 .80|^{t}$

Then we turn to the interpretation of the results.

In accordance with the adopted designations of variables, technical maintenance and repairs of instrumentation and automation of elevators, starting protection equipment should be transferred to a specialised repair organisation, and repairs of power and lighting networks should be carried out internally.

The cost of implementing the maintenance and repair schedule, corresponding to the optimum management vector, would be 473669.5 roubles.

\section{Conclusions}

1. An algorithm for managing the production process of maintenance and repair of electrical equipment has been developed.

2. The task of managing the production process of maintenance and repair of electrical equipment of agricultural enterprises according to the schedule of maintenance and repair is formulated as follows: at given relationship equations and constraints to find and implement a control algorithm that ensures minimization of values of indicators of technical and economic efficiency.

3. Optimization of scheduled works schedule was carried out taking into account the composition of performers and specific location of agricultural facilities.

\section{References}

1. V. G. Zhdanov, E. A. Logacheva Technologies and technical means of mechanized production of crop and animal products, 86, 208-217 (2015)

2. E. Lisin, A. Amelina, W. Strielkowski, V. Lozenko, O. Ziyvko Applied Mathematical Sciences, 9 (140), 6997-7010 (2015)

3. M. Lips, F. Burose International Journal of Agricultural Management. 1, 40-46 (2012)

4. V.I. Ignatov, V.S. Gerasimov, S.A. Buryakov, M.S. Mordasova Machinery and Equipment for Rural Area. 37-41 (2019)

5. I. Trunova, O. Miroshnyk, O. Savchenko, O. Moroz, V. Pazyi, T. Shchur, R. Kasner, P. Bałdowska-Witos Journal of Physics: Conference Series. 1781 (2021).

6. V. G. Zhdanov, E. A. Logacheva Agricultural Bulletin of Stavropol Region. 2 (18), 36-40 (2015)

7. P. V. Leshchilovsky, T. V. Kiyan, Belarusian Economic Journal, 4, 36-45 (2008) 